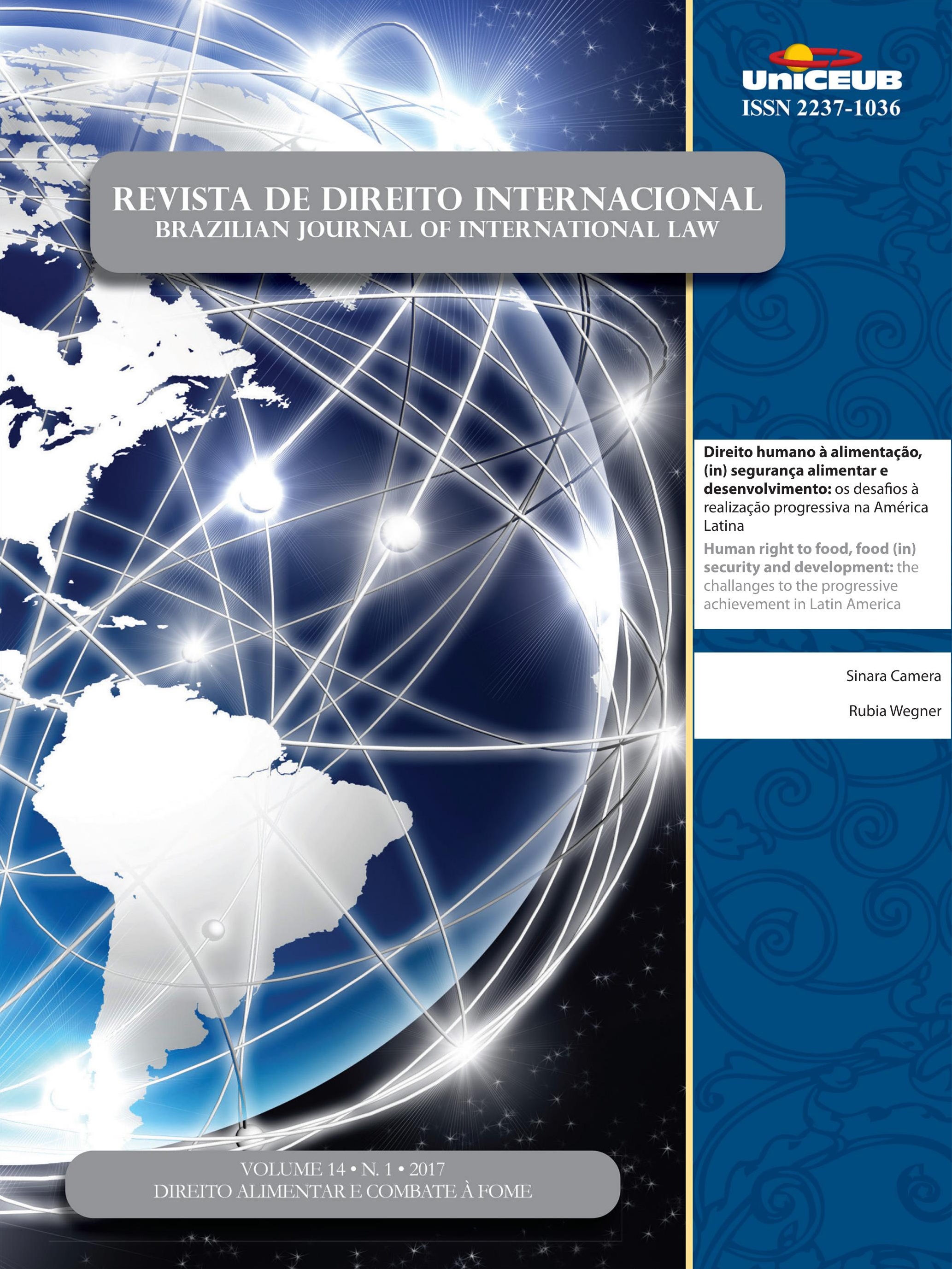




\section{Sumário}

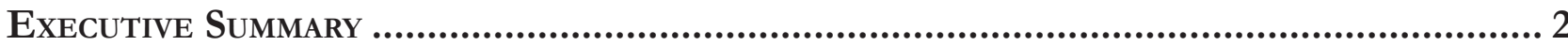

Daniel Balaban

Crônicas Sobre o Direito Alimentar e o Combate À Fome .............................................. 5

South-South Food and Nutrition Security promotion: the Brazilian experience

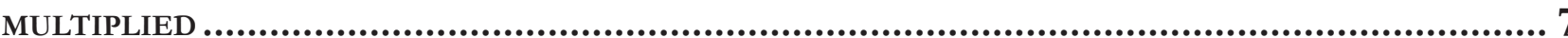

João Almino

Access to Food as a Human Right: Brazil, WFP and South-South Cooperation .......10 Carlos R. S. Milani

Dossiê temático: Direito Alimentar e Combate à Fome 13

WFP'S ROLE IN BUILDING SUSTAINABLE BRIDGES BETWEEN THE RIGHT TO ADEQUATE FOOD AND THE FREEDOM FROM HUNGER 15

Christiani Amaral Buani e Bruno Valim Magalhães

Direito humano À ALIMENTAÇÃo, (IN) SEgURANÇA ALIMENTAR E DESENVOLVIMENTO: OS DESAFios à REALIZAÇão PROGRESSIVA Na AMÉrica LATINa

Sinara Camera e Rubia Wegner

STATE'S INTERNATIONAL RESPONSIBILITY FOR THE HUMAN RIGHT TO FOOD: IMPLEMENTATION IN BRAZIL THROUGH AGROECOLOGY

Paula F. Strakos e Michelle B.B. Sanches

NegotiatiNg agRiCULtURE IN THE WORLD TRADE ORgANIZATION: FOOD SECURITY AS A NON-TRADE CONCERN.

Ana Luísa Soares Peres e Letícia de Souza Daibert

QUANDO HABITAR CORRESPONDE AO DIREITO HUMANO À ALIMENTAÇÃO

Fernanda Viegas Reichardt e Maria Elisa de Paula Eduardo Garavello 
The ROLE OF SUSTAINABLE LEARNING POLICIES ON THE FIGHT AGAINST

HUNGER IN ADULT EDUCATION.

Hiran Catuninho Azevedo

O DIREITO HUMANO E FUNDAMENTAL À ALIMENTAÇÃo ADEQUADA E À CONDIÇÃo

FEMININA NO PROGRAMA BOLSA FAMÍlIA: EMPODERAMENTO ÀS AVESSAS?

Rosalice Fidalgo Pinheiro e Laura Garbini Both

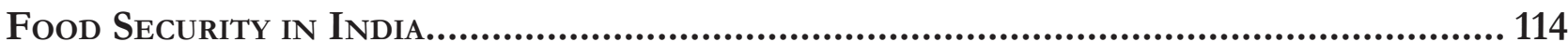

Ranjana Ferrão

SEguranÇA ALIMENTAR E A GOVERnANÇA ECONÔMICA GLOBAL

Danielle Mendes Thame Denny, Douglas de Castro, Alexandre Ricardo Machado, José Valverde Machado Filho e Gabrielle Fontes Witt

Outros Artigos.

The legal implications of the Draft Universal Declaration of the Rights of MANKIND

Catherine Le Bris

Litigating Indigenous Dispossession in THE Global Economy:

Law's Promises and Pitfalls................................................................................ 165

Charis Kamphuis

UNE DÉFINITION DU PRÉ-INVESTISSEMENT CONFORME À L'APPROCHE FRANÇAIS MAIS CONTRAIRE À L'APPROCHE AMÉRICAINE AU SEIN DES TRAITÉS BILATÉRAUX D'INVESTISSEMENTS IRANIENS

Peyman Dadras

CONFLITOS ENTRE REGULAÇÕES INTERNAS RELATIVAS À INTERNET E O DIREITO DO COMÉRCIO INTERNACIONAL: O PAPEL DA OMC PERANTE O SISTEMA DE COMPUTAÇÃO DA NUVEM ............238

Alice Rocha da Silva e Filipe Rocha Martins Soares

Prélèvement: origem, EVoluÇão e ocaso do Privilégio NAS SuCESSÕes INTERNACIONAIS NA FRANÇA

Fernando Pedro Meinero 
OS CONTRATOS INTERNACIONAIS DE FINANCIAMENTO E O CENTRO FINANCEIRO DE

Nova IorQue: CONSIDERAÇões SOBRE A AUTONOMIA DA VONTADE

Fernanda Torres Volpon

Mercosul e o Meio ambiente: ANÁlise da tUTELA REgional AMBIENTAL 284 Clarissa Ferreira Macedo D'Isep

Ainda (E uma Vez MAis) o SILÊNCIO QUe ENTOA O TRIUNFo De Lewis Carrol: A Regra N ${ }^{\circ} 42$ do Supremo Tribunal Federal

Thiago Aguiar Pádua e Bruno Amaral Machado

\section{A Natureza Jurídica do Sistema de Solução de Controvérsias da OMC} E DE SuAs Decisões: Solucionando um Imbróglio 316

Camila Capucio

Brics: Desafios do DESENVOLVIMENTO ECONÔMICO E SOCIOAMBIENTAI Magno Federici Gomes e Luís Eduardo Gomes Silva

REVER OU ROMPER COM VESTFÁLIA? POR UMA RELEITURA DA EFETIVA CONTRIBUIÇÃO DOS ACORDOS DE PAZ DE 1648 À CONSTRUÇÀO DO MODELO VESTFALIANO DE ESTADOS.

Luiz Magno Pinto Bastos Junior

Justiça de Transição EM SUA GÊNESE: A Alemanha Pós-NAZismo 378 Bruno Galindo

Quando JUlgar SE TORNa UM ESPETÁCulo: A INTERAÇão ENTRE o Supremo Tribunal Federal e a opinião pública, A PARTIR de REFlexões da LITERATURA ESTRANGEIRA

Patrícia Perrone Campos Mello

TolerânCia E refugio: um ENSAIO A PARTIR do ACORdo EU-TurQuia 425 Flávia Cristina Piovesan e Ana Carolina Lopes Olsen 


\title{
Direito humano à alimentação, (in) segurança alimentar e desenvolvimento: os desafios à realização progressiva na América Latina*
}

\author{
Human right to food, food (in) security \\ and development: the challanges to the \\ progressive achievement in Latin America
}

Sinara Camera**
Rubia Wegner***

\section{Resumo}

Desde a Conferência da Food and Agriculture Organization (FAO) de 1996, o direito humano à alimentação foi estabelecido como obrigação dos Estados nacionais. À comunidade internacional coube o papel de garantir que, nos países periféricos, fossem criados mecanismos de implementação de controle dessas obrigações. O que está em questão é garantir o acesso ao alimento e, nesse aspecto, além da geração de emprego e renda, estão a distribuição e a comercialização dos alimentos. Esses elos da cadeia ocorrem, especialmente, nos países subdesenvolvidos à revelia do setor privado que, em grande medida, são empresas transnacionais. O presente texto visa analisar, interdisciplinarmente, essas questões, à luz das medidas adotadas pelos países latino-americanos e europeus. A metodologia adotada nessa pesquisa teórica é bibliográfica e descritiva. Assim, serão analisados: a) os processos de internacionalização e diversificação dos direitos humanos forjando a criação de novos direitos a serem protegidos, como o direito humano à alimentação; b) a realização progressiva do direito humano à alimentação e do regime alimentar internacional em termos de desenvolvimento econômico; c) a questão da segurança alimentar e nutricional e a progressiva realização do direito humano à alimentação, a partir das experiências da União Europeia e América Latina. Nesse contexto, verifica-se que o maior desafio à realização progressiva do direito humano à alimentação na América Latina está nos fatores econômicos e estruturais e referentes à evolução do sistema agroalimentar internacional.

Palavras-chave: Direito humano à alimentação. Segurança alimentar e nutricional. Regime alimentar internacional. Desenvolvimento. América Latina.

\section{Abstract \\ ABSTRACT}

\footnotetext{
Estadual de Campinas (UNICAMP/SP/Brasil). Departamento de Ciências Econômicas da Universidade Federal Rural do Rio de Janeiro. E-mail: rubicawegner@gmail.com

** Professora do Curso de Direito das Faculdades Integradas Machado de Assis (FEMA/ Universidade do Vale do Rio dos Sinos (UNISINOS/RS/Brasil), com período de doutoramento sanduíche na Universidade de Sevilla (US/ cana, área de concentração Direito do Mestrado em Integração Latino-Americana (MILA) da Universidade Federal de Santa Maria (UFSM/ RS/Brasil). E-mail: aiacamera@hotmail.com
}

Since the Food and Agriculture Organization (FAO) Conference in 1996, the human right to food was established as an obligation of national states. To the international community fit the role to ensure that, in the 
peripheral countries, implementation of control mechanisms of these obligations were created. The question was to ensure access to food and, in this respect, in addition to generating employment and income, are the distribution and marketing of food. These links in the chain occur especially in developing countries by default private sector that largely are transnational companies. This text aims to analyze interdisciplinar these issues in the light of the measures adopted by Latin American and European countries. Thus, will be analyzed a) the internationalization and diversification of human rights forging the creation of new rights to be protected, such as the human right to food; b) about the progressive achievement of human right to food in the international food regime in terms of economic development; and c) the issue of food and nutricional security and the progressive achievement of human right to food from european union and latin america experiences. In this context, the greatest challenge to the progressive achievement of the human right to food in the Latin Ameri$\mathrm{ca}$ is in the economic and structural factors and related to the evolution of the international agrifood system.

Keywords: Human right to food. Food and nutricional security. International food regime. Development. Latin America.

\section{INTRODUÇÃo}

Desde os arranjos que antecedem a Declaração Universal dos Direitos Humanos, de 1948, há esforços no sentido de promover a realização desses direitos, buscando-se envolver os Estados a não só comprometerem-se na sua garantia, mas também a criarem meios para efetivá-los. Para isso, as leis são essenciais, mas a sua existência não é suficiente; faz-se necessário o desenvolvimento de políticas que viabilizem a sua concretização. Diante dos cenários de aprofundamento e diversificação dos direitos humanos, notadamente após a Década de 1990, nos processos de afirmação internacional e nacionais, surgem novos direitos fundamentais à dignidade humana.

Nesse catálogo está o direito humano à alimentação (DHA), estabelecido na Conferência da Food and Agriculture Organization (FAO) de 1996, como obrigação dos Estados Nacionais pela sua efetivação. Determinou-se, também, que à comunidade internacional caberia o papel primordial de garantir que, nos países periféricos, erigissem-se mecanismos com vistas a torná-lo mais do que um jogo abstracionista. Essas diretrizes buscam permitir acompanhar instrumentos dos Estados e da comunidade internacional, notadamente da FAO, e suas articulações práticas. O que está em questão é garantir o acesso ao direito a alimentos e, nesse aspecto, além de, reconhecidas as condições à segurança alimentar, observada a geração de emprego e renda, estão a distribuição e a comercialização dos alimentos.

Nesse contexto, relações econômicas, comerciais e financeiras, entenda-se — se consubstanciam às dificuldades de realização do DHA. Em 2013, o índice de preços dos alimentos da FAO marcou em média 209,9 pontos, estando 1,6\% abaixo do registrado em 2012 e $9,1 \%$ menor do que o relativo a 2011, quando este índice alcançou níveis inauditos. Cereais - em crescimento próximo a 7,2\% em relação a 2012 —, óleos e açúcar tiveram seus preços reduzidos em função do aumento da sua oferta, enquanto que carne - alimentos proteicos de modo geral — seguiu com preço elevado.

A importância desse artigo se encontra no contexto de aumento dos índices de fome e desnutrição no mundo e a segurança alimentar e nutricional ${ }^{1}$ foi, amplamente, tratada em termos dos limites ao acesso e as condições da comercialização e distribuição de alimentos foram discutidas em fóruns mundiais. No entanto, os avanços para solucionar esse problema foram limitados, mas não podem ser considerados ineficazes de todo. Entre 2010 e 2012, aproximadamente 870 milhões de pessoas não consumiram alimentos a contento das necessidades nutricionais diárias; desse total, pelo menos 852 milhões vivem em países subdesenvolvidos. ${ }^{2}$ Ainda de acordo com dados da Organização das Nações Unidas para Fome e Alimentação (FAO), em 2009, eram mais de um bilhão de pessoas em situação de fome no mundo, das quais 63\% estariam na África.

Dessa forma, o presente artigo visa analisar as ques-

1 Segurança alimentar e nutricional é a realização do direito de todos ao acesso regular e permanente a alimentos de qualidade, em quantidade suficiente, sem comprometer o acesso a outras necessidades essenciais, tendo como base práticas alimentares promotoras de saúde, que respeitem a diversidade cultural e que sejam social, econômica e ambientalmente sustentáveis. MALUF, Renato Sérgio. Segurança Alimentar e Desenvolvimento Econômico na América Latina: o caso do Brasil. Revista de Economia Política, São Paulo, n.15, p.134-140, 1995.

2 Dados de 2013, retirados da Food and Agriculture Organization, disponíveis em: < http://www.fao.org/home/en/>. 
tões da progressiva realização do direito humano à alimentação nos Estados, observando-se as condições para a segurança alimentar e nutricional, a partir da análise dos principais movimentos e mecanismos estatais na América Latina em comparação com medidas da União Europeia. Essa comparação é uma forma de se pensar a relação entre realização do direito humano à alimentação com desenvolvimento econômico. Para tanto, dividiu-se o presente trabalho em três momentos: primeiramente serão analisados. Assim, serão analisados os processos de internacionalização e diversificação dos direitos humanos forjando a criação de novos direitos a serem protegidos, como o direito humano à alimentação. Em um segundo momento, discorrer-se-á sobre a realização progressiva do direito humano à alimentação e do regime alimentar internacional em termos de desenvolvimento econômico. Por fim, será tratada a questão da segurança alimentar e nutricional e a progressiva realização do direito humano à alimentação, a partir das experiências da União Europeia e América Latina.

\section{Direito humano à alimentação: Contexto DO SURGIMENTO E DA AFIRMAÇÃO}

A partir do pós-Segunda Guerra Mundial, inicia-se a expansão dos direitos humanos, impulsionada pela internacionalização desses direitos, sendo colocados como referencial ético para orientar as relações intra e interestais. A ruptura no paradigma de direitos humanos, vigente até aquele momento, abre uma senda para a reflexão acerca da necessidade da reconstrução de cenários: interno, com o esforço adequação (em maior ou menor medida, nos diferentes espaços do Globo) a novos padrões éticos e morais; e externo, com o surgimento do Direito Internacional dos Direitos Humanos (DIDH).

O desenvolvimento do DIDH consiste na construção de um sistema de normas internacionais, que preveem procedimentos e firmam instituições para garantir a implementação dessa nova concepção de direitos humanos, promovendo mundialmente o seu respeito nos e pelos Estados. Ainda, há que se considerar, nesse processo de afirmação de uma ordem internacional para a proteção dos direitos humanos, a própria criação da Organização das Nações Unidas $(\mathrm{ONU})^{3}$ e das suas

3 Destarte, a busca pelos objetivos da ONU é marcada pela crescente normatização internacional dos direitos humanos e leva a so- agências especializadas. ${ }^{4}$ A expansão de organizações internacionais com propósitos de cooperação amplia, significativamente, a agenda internacional para que se possam conjugar novas e emergentes preocupações na proteção dos direitos humanos.

Como documento inaugural, tem-se a Declaração Universal de 1948, que a concepção contemporânea de Direitos Humanos e suas intenções de universalidade e indivisibilidade. A ela se somam os Pactos Internacionais sobre Direitos Civis e Políticos e o sobre Direitos Sociais, Econômicos e Culturais, de 1966. Os três documentos passam a representar o International Bill of Human Rights (a Carta Internacional dos Direitos Humanos), declarada jus cogens pela Corte Internacional de Justiça (CIJ), em 1970. À Carta foram acrescidos uma série de amplos tratados especiais de direitos humanos (proscrição da tortura, extinção das formas de discriminação em relação à mulher etc.). ${ }^{5}$

Ainda, na Conferência Mundial dos Direitos Humanos de Viena, promovida pelas Nações Unidas, em 1993, foi reforçada a validade universal dos direitos humanos, apesar de uma certa resistência dos países asiáticos, que tentavam relativizá-los e de uma outra cosmovisão da interpretação islâmica dos direitos humanos. A Declaração de Direitos Humanos de Viena, em seu \ $5^{\circ}$, afirma: "todos os direitos humanos são universais, interdependentes e interrelacionados. A comunidade internacional deve tratar os direitos humanos globalmente, de forma justa e equitativa, em pé de igualdade e com a mesma ênfase."

ciedade internacional a não mais admitir a soberania como obstáculo à sua atuação para evitar ou cessar violações. Dessa forma, aumentam as pressões da comunidade internacional para que as condutas estatais estejam compassadas com a observância dos direitos fundamentais dos indivíduos que se encontram em seu território. A ONU tem como objetivos: a defesa dos direitos fundamentais do ser humano; garantir a paz mundial, colocando-se contra qualquer tipo de conflito armado; buscar mecanismos que promovam o progresso social das nações; criar condições que mantenham a justiça e o direito internacional. ORGANIZAÇÃO DAS NAÇÕES UNIDAS. Carta das Nações Unidas. 1945. Disponível em: <http:// www.un.org/spanish/Depts/dpi/portugues/charter/index.htm>. Acesso em: 10 out. 2016.

4 As agências especializadas, como a Organização das Nações Unidas para a Alimentação e Agricultura (FAO), a Organização das Nações Unidas para a Educação, Ciência e Cultura (UNESCO), a Organização Mundial da Saúde, entre outras, são criadas mediante acordo firmado por Estados, vinculadas às Nações Unidas, mas possuem autonomia, com independência jurídica e de conteúdo.

5 BIELEFELDT, Heiner. Filosofia dos Direitos Humanos. Trad. Dankwart Bernsmüller. São Leopoldo: UNISINOS, 2000, p.11. 6 ORGANIZAÇÃO DAS NAÇÕES UNIDAS. Declaração e 
A Década das Conferências, como ficou conhecida a de 1990, exsurge a fim de encontrar respostas à complexidade das temáticas assumidas como prioridades, diante da inter-relação entre segurança, economia, direitos humanos e democracia, apresentando a conexão global entre elas. Esse contexto fez com que se disseminasse a concepção de que

[...] se os temas abordados eram globais, o que ocorresse numa área afetaria as outras. A indução lógica poderia levar também a uma interpretação político-jurídica se não kantiana, de imperativos éticos categóricos, pelo menos grociana, de interesses compartilhados: num mundo efetivamente globalizado, o interesse de todos seria o interesse de cada um; as diferenças individuais de enfoques podem e devem ser administradas pelo Direito. Em lugar da abstenção perante as jurisdições nacionais, as conferências propunham esforços abrangentes, de todos os atores influentes.

A Declaração de Viena e o Programa de Ação, considerando as grandes mudanças ocorridas no cenário internacional, incluem, como temas fundamentais: a promoção e o incentivo do respeito aos direitos humanos e às liberdades fundamentais para todos; do respeito ao princípio da igualdade de direitos e da autodeterminação dos povos; da paz; da democracia; da justiça; da igualdade; do Estado de direito; do pluralismo; do desenvolvimento; das melhores condições de viver e de solidariedade. Tudo a fim de dar novos passos no compromisso da comunidade internacional, com vistas a alcançar progressos substanciais nos direitos humanos. ${ }^{8}$ Em relação ao cenário de desenvolvimento de novos direitos a serem protegidos, surge em 1996, na Conferência da FAO, o direito humano à alimentação. Os Estados Nacionais devem garantir a sua efetivação. À comunidade internacional cabe o papel de garantir que, nos países periféricos, erijam-se mecanismos com vistas a torná-lo mais do que um jogo abstracionista. O que está em questão é garantir o acesso ao alimento e, nesse aspecto, a geração de emprego e renda, bem como a distribuição e a comercialização dos alimentos.

Programa de Ação de Viena. 1993. Disponível em: < http:/ /www. pge.sp.gov.br/centrodeestudos/bibliotecavirtual/instrumentos/ viena.htm>. Acesso em: 10 out. 2016.

7 ALVES, José Augusto Lindgren. Relações Internacionais e Temas Sociais. A Década das Conferências. Brasília: IBRI, 2001. 8 ORGANIZAÇÃO DAS NAÇÕES UNIDAS. Declaração e Programa de Ação de Viena. 1993. Disponível em: < http://www. pge.sp.gov.br/centrodeestudos/bibliotecavirtual/instrumentos/ viena.htm>. Acesso em: 10 out. 2016.
O direito humano à alimentação (DHA) vem adquirindo maior importância no embasamento de programas voltados para garantir a segurança alimentar e nutricional (SAN) e de leis de segurança alimentar em diferentes países. A perspectiva desse direito traça elementos específicos para a atuação do Estado no tocante ao acesso aos alimentos pela população, podendo ser definido por:

[...] ter acesso, de maneira regular, permanente e livre, seja diretamente, seja mediante compra em dinheiro, a uma alimentação quantitativa e qualitativamente adequada e suficiente, que corresponda às tradições culturais da população a que pertence o consumidor e que garanta uma vida psíquica e física, individual e coletiva, livre de angústias, satisfatória e digna. ${ }^{9}$

A construção desse conceito foi marcada por um longo caminho de discussões em organismos internacionais, ${ }^{10}$ tendo em vista a complexidade que o tema envolve. Em outras palavras, os embates na sua construção se relacionavam com a definição os responsáveis pelo seu cumprimento, as punições cabíveis, custos e recursos e, ainda, dois aspectos mais abstratos: a sua definição e orientação para ser cumprido pelo mundo subdesenvolvido partia de países ricos, impulsionadores de uma 'ordem alimentar mundial' extremamente desfavorável para as populações pobres dos países subdesenvolvidos. Além disso, trata-se de um direito de todas as pessoas, mas aquelas afetadas pela fome se destacariam das demais em termos de medidas e de programas adotados sob a definição de DHA. Além disso, por falta de condições físicas, psicológicas, as pessoas em situação de fome não teriam capacidade de atuarem como sujeitos do seu direito a uma alimentação adequada. ${ }^{11}$

Não se coloca em dúvida o quão imprescindível é o consumo diário e em quantidades adequadas de nutrientes pela população de um país. Sabe-se, também,

9 FOOD AND AGRICULTURE ORGANIZATION. Diretrizes voluntárias: em apoio à realização progressiva do direito à alimentação adequada no contexto da segurança alimentar nacional. Roma, 2004. Disponível em: <http://www.fao.org/docrep/006/ Y5160s/Y5160s00.htm>. Acesso em: 12 out. 2016, p. 04. Para maiores esclarecimentos e reflexões se indica: BOURRINET, Jacques; FLORY, Maurice. L'ordre alimentaire mondial. Economica: Paris, 1982.

10 Com base nas leituras feitas, acredita-se que o debate, nos organismos multilaterais, sobre essa limitação conceitual tenha se intensificado nos anos 1980.

11 HABIB, Bernard. Droits de l'homme et alimentation. In: BOURRINET, Jacques; FLORY, Maurice L'ordre alimentaire mondial. Economica: Paris, 1982. 
que essa imprescindibilidade por si só não determina que todos tenham acesso a alimentos. Como exemplo, em 2009, havia um bilhão de subnutridos no mundo, dos quais 53 milhões eram latino-americanos. ${ }^{12}$ Alimentar-se é uma necessidade básica do ser humano, que requer uma regulamentação pública com vistas a garanti-la em condições adequadas à população. Os números ligados à situação alimentar no mundo, de modo geral, mostram que os Estados nacionais, especialmente os não desenvolvidos, não alcançaram uma fórmula para solucionarem a inacessibilidade aos alimentos.

Mobilizações internacionais destinadas a transformar, positivamente, o quadro da fome no mundo, no que se destacam os Objetivos para o Desenvolvimento do Milênio do que a assinatura das diretrizes voluntárias é resultante, os números parecem difíceis de serem contornados favoravelmente:

\begin{abstract}
Aunque se han logrado progresos significativos hacia la consecución de la meta establecida en los objetivos de desarrollo del Milenio (ODM) de reducir a la mitad la proporción de personas subnutridas, será necesario acelerar el ritmo a fin de poder alcanzar el objetivo para el año 2015. Lograr el objetivo de la CMA de reducir el número absoluto de personas hambrientas de casi 800 millones a 400 millones resultará más difícil, pues para ello se requerirán progresos mucho más rápidos. ${ }^{13}$
\end{abstract}

Por outro lado, tão ou mais importante do que o estabelecimento do seu conceito é a importância da sua materialização: "[...] food security stands as a fundamental need, basic to all human needs and the organisation of social life. Access to necessary nutrients is fundamental, not only to life per se, but also to stable and enduring social order." "N No sentido colocado por Josué de Castro, em Geopolitica da Fome, tratar da questão do acesso aos alimentos significa a valorização fisiológica do homem. A carência de nutrientes na dieta alimentar constitui fator para reduzir a capacidade da população em se desenvolver como seres humanos plenos. ${ }^{15}$

12 FOOD AND AGRICULTURE ORGANIZATION. El estado mundial de la agricultura y la alimentación. Roma, 2009. Disponível em: <http://www.fao.org/docrep/012/i0680s/i0680s. pdf $>$. Acesso em: 12 out. 2016.

13 FOOD AND AGRICULTURE ORGANIZATION. El estado mundial de la agricultura y la alimentación: comercio agrícola y pobreza ¿puede el comercio obrar en favor de los pobres? Roma, 2005. Disponível em: <ftp://ftp.fao.org/docrep/fao/008/ a0050s/a0050s_full.pdf >. Acesso em: 12 out. 2016.

14 HOPKINS apud MAXWELL, Simon. Food security: a postmodern perspective. Food Policy, v.21, n.2, p.155-170, 1996, p.158. 15 CASTRO, Josué de. Geopolítica da Fome: ensaio sobre os problemas de alimentação e de população. v.1. São Paulo: Brasil-
Nos últimos anos, tem-se percebido um reforço da importância de se alcançar a condição de Segurança Alimentar e Nutricional em que a realização progressiva do Direito Humano à Alimentação estaria concretizada. Representa considerar, normativamente, o alimento como um requerimento para a existência humana e uma exigência das/para as atividades humanas. É essencial; deve ser tomado pela sua totalidade, caso contrário, não seria imprescindível. Para se efetivar, a alimentação precisa ser encarada em toda sua complexidade: condições da produção agroalimentar, nível de desenvolvimento do país, confiança nas instituições.

Entretanto, não existem determinações claras sobre o melhor método para construir o caminho para a realização do DHA, isto é: garantir o acesso ao alimento com base na transferência de renda monetária ou atrelada à compra de alimentos. Afinal, se ao Estado cabe obrigação de garantir alimentação suficiente e adequada, então, uma política de transferência de renda para se enquadrar, conceitualmente, na garantia da segurança alimentar deve ser complementada com dispositivos para tal. ${ }^{16}$

O direito ao desenvolvimento econômico está, reiteradamente, atrelado ao direito alimentar. ${ }^{17}$ Entretanto, a efetivação do direito humano à alimentação, a garantia de que será, progressivamente, realizado nos países não desenvolvidos, envolve toda a comunidade internacional. Além disso, evidencia o hiato existente entre as economias avançadas e periféricas, quanto à inserção econômica internacional.

\section{A ReAlização progressiva do direito HUMANO À ALIMENTAÇÃO, REGIME ALIMENTAR INTERNACIONAL E DESENVOLVIMENTO}

Nas Diretrizes Voluntárias - documento elaborado pela $\mathrm{FAO}$, em $2004^{18}$ - estabelece-se a recomendação

iense, 1968.

16 TAKAGI, M. et al. A política de segurança alimentar e nutricional do Brasil a partir do programa Fome Zero. In: ORTEGA, A.C.; ALMEIDA FILHO, N. Desenvolvimento territorial, segurança alimentar e economia solidária. Campinas-SP: Editora Alínea. 2006, p.159-184.

17 EIDE, Asbjorn. Human rights requirements to social and economic development. Food Policy, v. 21, n. 1, 1996, p. 23-39.

18 Sua mais recente edição foi lançada em 2015, mas o texto segue substancialmente sendo o aprovado em 2004. Pode-se acessar a edição de 2015 em: <http://www.fao.org/3/b-y7937o.pdf>. 
para que todos os atores internacionais assumam responsabilidades pela alimentação. Ressalta, também, o comércio internacional como importante mecanismo para o estabelecimento da Segurança Alimentar e Nutricional por meio da promoção do desenvolvimento econômico que ele deve acarretar. Atenta para o papel da Organização Mundial do Comércio (OMC) na regulamentação de um comércio menos desigual entre países desenvolvidos e não desenvolvidos. ${ }^{19}$ Ademais, no comércio agrícola pesam os subsídios e outras tarifações utilizadas pelos países desenvolvidos.

Além disso, o referido documento ressalta a importância da atuação conjunta da comunidade internacional para a realização progressiva do direito humano à alimentação, colocando-a em termos de cooperação técnica, descrita como segue:

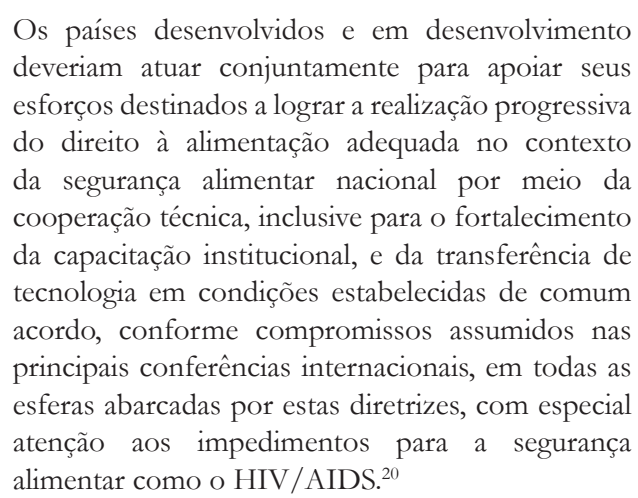

Entretanto, há elementos caracterizadores do sistema alimentar mundial que tendem a interferir na realização progressiva do direito humano à alimentação seriam: concentração de poder e de recursos nas grandes companhias de produção e de distribuição de alimentos, sistemas de ofertas de alimentos que excluem os pequenos agricultores, que produzem em menor escala, comércio internacional excludente até mesmo nas negociações para arrefecimento de barreiras. ${ }^{21}$

Numa perspectiva histórica, a constrição de alimentos detonada pela $2^{a}$ Guerra Mundial nos países desen-

19 FOOD AND AGRICULTURE ORGANIZATION. Diretrizes voluntárias: em apoio à realização progressiva do direito à alimentação adequada no contexto da segurança alimentar nacional. Roma, 2004. Disponível em: <http://www.fao.org/docrep/006/ Y5160s/Y5160s00.htm>. Acesso em: 12 out. 2016.

20 FOOD AND AGRICULTURE ORGANIZATION. Diretrizes voluntárias: em apoio à realização progressiva do direito à alimentação adequada no contexto da segurança alimentar nacional. Roma, 2004. Disponível em: <http://www.fao.org/docrep/006/ Y5160s/Y5160s00.htm>. Acesso em: 12 out. 2016.

21 MAXWELL, Simon; SLATER, Rachel. Food policy: old and new. Food Policy, v.21, n.5-6, 2003, p.531-553. volvidos, sobretudo, deu à autossuficiência de alimentos um caráter praticamente de segurança nacional e de condição básica para existência de segurança alimentar. Nesse cenário nasce a Organização das Nações Unidas para a Alimentação e a Agricultura (FAO), em 16 de outubro de $1945 .^{22}$ A pauta era organizar os alimentos e a agricultura com vistas a orientar a produção e a distribuição dos alimentos e evitar situações de carestia.

Essas discussões, para ordenar a agricultura internacional em termos de política comercial, evidenciaram os protecionismos dos EUA e Europa para com o setor. Destarte esses países perseguirem o livre comércio, esse arranjo internacional para agricultura fez valer os interesses protecionistas dos países avançados. Os EUA, por exemplo, conseguiram manter suas medidas de controle de importação e comércio administrado por meio do GATT (General Agreement on Tariffs and Trade ou Acordo Geral de Tarifas e Comércio), em detrimento da Organização Internacional do Comércio. A impossibilidade desses países se entenderem, EUA e Grã-Bretanha principalmente, solapou a emergência de uma Comissão Internacional de Alimentos (World Food Board) e, por conseguinte, de um planejamento multilateral eficiente na distribuição de alimentos. Assim, a organização dos alimentos se tornou nacionalmente regulado. ${ }^{23}$

O sistema de comércio pró-desenvolvimento é aquele que se fundamenta em países ricos reduzindo suas tarifas e subsídios para os países menos desenvolvidos, ainda que a concorrência imperfeita dos mercados impeça afirmar que o livre comércio poderia beneficiar todos os produtores de commodities agrícolas dos países em desenvolvimento. ${ }^{24}$

As desregulamentações ${ }^{25}$ do sistema financeiro ame-

22 A FAO é a Organização das Nações Unidas para a Agricultura e Alimentação. Maiores informações sobre a Organização podem ser acessadas em: <http://www.fao.org/home/en/>, ou na FAO Brasil: <https://www.fao.org.br/>.

23 FRIEDMANN, Harriet. Uma Economia Mundial de Alimentos Sustentável. In: BELIK, W.; MALUF, R.S. (orgs.) Abastecimento e Segurança Alimentar: os limites da liberalização. Campinas: IE/Unicamp, 2000, p. 1-22.

24 SHAIKH, Anwar. Globalization and the myth of free trade. New School University: New York, 2003.

25 A revolução dos derivativos foi essencial para a estabilização dos mercados de moedas e fomentando a capacidade global de distribuição dos títulos do Tesouro americano, a partir da derrocada do câmbio fixo. Redução dos custos dentro dos EUA, com o aumento das economias de escala adquiriu função anti-inflacionária sob o dólar ancorando o capitalismo mundial. Não se tratava de redução do papel do Estado americano, mas da defesa do fim da regulação. 
ricano e europeu iniciadas entre as décadas de 1970 e 1980, e aprofundadas nas décadas que se seguiram, tornam ainda mais complexa a relação entre países desenvolvidos e em desenvolvimento no sistema alimentar global (Quadro 1). Dessa forma, os EUA se tornam o epicentro da análise dos fatores influentes sobre a realização progressiva do DHA. Em uma perspectiva histórica, o despejo de grãos, em economias subdesenvolvidas, promovido pelos EUA no auge daquele processo na década de 1980, permitiu o reforço deste, além de tornar ainda mais difícil o acesso à alimentação nesses países (Quadro 1). Veja-se o tratamento à agricultura dispensado pelos EUA e sua relação com a posição do mercado internacional entre 1900 e1990:

\begin{tabular}{|c|c|c|}
\hline Período & Contexto & Tratamento à agricultura \\
\hline $\begin{array}{l}\text { Corolário da } \\
\text { Doutrina Mon- } \\
\text { roe de Theodore } \\
\text { Roosevelt, } 1904\end{array}$ & $\begin{array}{l}\text { Construção uma } \\
\text { área de livre } \\
\text { comércio especial- } \\
\text { mente com seus } \\
\text { vizinhos }\end{array}$ & $\begin{array}{l}\text { Logística eficiente e acor- } \\
\text { dos tarifários para comer- } \\
\text { cializar bens agrícolas ao } \\
\text { menor custo. }\end{array}$ \\
\hline Crise de 1929 & $\begin{array}{l}\text { Produção indu- } \\
\text { strial representava } \\
42 \% \text { do total } \\
\text { mundial, embora } \\
\text { houvesse desigual- } \\
\text { dade da economia } \\
\text { doméstica }\end{array}$ & $\begin{array}{l}\text { Estava particularmente } \\
\text { vulnerável a desvalori- } \\
\text { zação de preços. }\end{array}$ \\
\hline $\begin{array}{l}\text { Entre as décadas } \\
\text { de } 1940 \text { e } 1970\end{array}$ & $\begin{array}{l}\text { Comércio exterior } \\
\text { era mecanismo } \\
\text { para compensar } \\
\text { excesso de capaci- } \\
\text { dade e penetrar no } \\
\text { aparato de policy- } \\
\text { making dos países } \\
\text { europeus objeto } \\
\text { do Plano Marshall. }\end{array}$ & $\begin{array}{l}\text { As exportações da agri- } \\
\text { cultura eram muito im- } \\
\text { portantes, porém se man- } \\
\text { tinham em apenas } 5 \% \text { do } \\
\text { PIB de } 1929 .\end{array}$ \\
\hline 1970-1980 & $\begin{array}{l}\text { Consolidar sua } \\
\text { posição hegemôni- } \\
\text { ca a partir da sua } \\
\text { 'base imperial } \\
\text { doméstica'. }\end{array}$ & $\begin{array}{l}\text { Vantagens competitivas } \\
\text { na agricultura; expansão } \\
\text { considerável de milho, } \\
\text { produtividade agrícola } \\
\text { superior à de várias } \\
\text { indústrias; commodities } \\
\text { agrícolas com preços } \\
\text { elevados. Expansão entre } \\
\text { essas décadas de mais de } \\
\text { 300\% das exportações } \\
\text { agrícolas globais. }\end{array}$ \\
\hline
\end{tabular}

$\overline{\text { A liberalização das finanças e a volatilidade aceleraram a competição }}$ e a mobilidade de capital ante a persistência da pressão inflacionária, dos salários e aumento dos preços de commodities, nos 1970s. Com a rejeição, em 1976, do keynesianismo são definidas as políticas próglobalização ou a estratégia de acumulação liderada pelas finanças, como pode-se verificar em PANITCH, Leo; GINDIN, Sam. The making of global capitalism: the political economy of American empire. Verso: London, New York. 2012.

\begin{tabular}{|c|c|c|}
\hline Período & Contexto & Tratamento à agricultura \\
\hline $\begin{array}{l}1974 \text { a década de } \\
1980\end{array}$ & $\begin{array}{l}\text { Posição desta } \\
\text { potência em } \\
\text { relação ao desen- } \\
\text { volvimento dos } \\
\text { países do Terceiro } \\
\text { Mundo; encora- } \\
\text { jamento desses } \\
\text { países a comprar } \\
\text { notas do Tesouro } \\
\text { americano, amém } \\
\text { dos petrodólares. } \\
\text { Grandes quantias } \\
\text { de dinheiro saíram } \\
\text { emprestadores } \\
\text { para tomadores } \\
\text { estrangeiros. } \\
\text { Bancos dos EUA } \\
\text { se tornaram a } \\
\text { primeira fonte de } \\
\text { financiamento de } \\
\text { balanços de paga- } \\
\text { mentos e de inve- } \\
\text { stimentos públicos } \\
\text { e privados. }\end{array}$ & $\begin{array}{l}\text { Promoção agressiva das } \\
\text { exportações agrícolas } \\
\text { estadunidenses para sub- } \\
\text { stituir ajuda alimentar aos } \\
\text { países subdesenvolvidos } \\
\text { (Trade Act). Entrada do } \\
\text { modelo agrícola estaduni- } \\
\text { dense nesses países, in- } \\
\text { duzindo a transformação } \\
\text { da agricultura familiar em } \\
\text { orientada para exportação } \\
\text { e agronegócio. O Primei- } \\
\text { ro Mundo exportava mais } \\
\text { bens agrícolas do que o } \\
\text { Terceiro Mundo. }\end{array}$ \\
\hline 1980-1987 & $\begin{array}{l}\text { Volatilidade finan- } \\
\text { ceira. Quebra da } \\
\text { bolsa. }\end{array}$ & \begin{tabular}{|l|} 
Adoção de políticas \\
protecionistas para en- \\
frentar alto desemprego, \\
devastação de parque \\
industrial e agrícola e \\
apreciação do dólar. \\
\end{tabular} \\
\hline $1987-1990$ & $\begin{array}{l}\text { Grandes firmas } \\
\text { de tecnologia } \\
\text { avançada; firmas } \\
\text { financeiras eram } \\
\text { principais atores } \\
\text { da Revolução } \\
\text { de TI }\end{array}$ & $\begin{array}{l}\text { Grandes avanços de bio- } \\
\text { tecnologia. }\end{array}$ \\
\hline \multicolumn{3}{|c|}{$\begin{array}{l}\text { Quadro 1. Tratamento à agricultura dado pelos EUA e sua relação } \\
\text { com a posição do mercado internacional. (1900-1990) } \\
\text { Fonte: Elaboração própria com base em PANITCH, Leo; } \\
\text { GINDIN, Sam. The making of global capitalism: the political } \\
\text { economy of American empire. Verso: London, New York. } 2012 .\end{array}$} \\
\hline
\end{tabular}

Em 2008, o aumento dos preços de alimentos afetou populações com menor poder aquisitivo em diferentes países. A quantidade de alimentos consumida por uma família foi reduzida, além de alimentos menos calóricos e menos nutritivos tomarem maior relevância em sua cesta de consumo. ${ }^{26}$ Estimativas da FAO relativas aos efeitos da 'crise alimentar' apontam para aumento de mais de 173 milhões de pessoas em situação de fome e desnutrição. A agricultura, mais especificamente, os grãos (commodity), passa a se enquadrar, cada vez mais, nos mercados futuros.

26 FOOD AND AGRICULTURE ORGANIZATION. El estado mundial de la agricultura y la alimentación. Roma, 2009. Disponível em: <http://www.fao.org/docrep/012/i0680s/i0680s. pdf $>$. Acesso em: 12 out. 2016. 
Como fatos recentes na agricultura e relacionados às relações econômicas - neste caso, financeiras, essencialmente - estão a financeirização da agricultura e a política de mudança da matriz energética impetrada por EUA e União Europeia. Em 2008, fundos de investimento controlavam entre 50 a $60 \%$ do comércio de commodity, ou seja, essas mercadorias passaram a ser tratadas como meros ativos financeiros: o preço do arroz, por exemplo, cresceu 31\% em março de 2008 e o do trigo, $29 \%$ em fevereiro de 2008 , o que teria estimulado investimentos em Wall Street da ordem de US\$ 130 bilhões. ${ }^{27} \mathrm{O}$ investimento externo direto (IED) da agricultura apresentaria, também, crescimento ao longo dos últimos anos. Para África e Ásia, esse investimento tem se mostrado mais atrativo. Além disso, o agronegócio, em termos gerais, foi mais favorável em termos de políticas de atração de investimento externo, em 2012. ${ }^{28}$

A necessidade de os países desenvolvidos buscarem diversidade energética, expressa em estratégias direcionadas a fomentar a seguridade nesse campo, foi sendo revelada por meio de estudos e assinatura de acordos com economias subdesenvolvidas ${ }^{29}$ que, em 2004, a publicação Estratégia para Agricultura, pela United States Agency for Internacional Development (USAID), consolidou no âmbito de instituições como Organização dos Estados Americanos (OEA), Banco Interamericano de Desenvolvimento (BID) e Comissão Econômica para América Latina e o Caribe (CEPAL), a ideia de que era necessária a substituição energética vinculada a uma nova forma de uso do solo e da água. É a multidimensionalidade da Iniciativa Energética Mesoamericana (IEM) que permite a exportação de agrocombustíveis para os EUA.

De fato, em 2000, a produção mundial de agrocombustíveis 315 milhões de barris por dia e, em 2009, essa

27 MCMICHAEL, Philip. A food regime analysis of the 'world food crisis'. Agriculture and Human Values, Springer, 31 July, 2009.

28 UNCTAD. Global value chains: investment and trade for development. World Investment Report 2013. New York e Genebra, 2013.

29 Deve-se destacar a "Alianza para el Uso Sustenible de La Energía" (AUSE), que visava tratar de temas como aumento dos investimentos, da promoção de energias limpas e diversificação de energias renováveis e os interesses dos EUA nessa aliança eram respaldados pelo BID, Cepal, ONU e Banco Mundial. TERÁN, Juan Fernando. La economía de los biocombustibles: una mirada a los proyectos hegemônicos para América Latina. In: Fernandes, Bernardo M. (Org.), Campesinato e agronegócio na América Latina: a questão agrária atual. São Paulo: Expressão Popular, 2008, p. 339-364. produção aumentou para 1,6 bilhão de barris por dia. ${ }^{30}$ Ainda com base na Unctad, seus picos de crescimento se deram no período de 2002 a 2008, com variação anual em torno de 30\%. A demanda mundial por terras, com base em dados do Banco Mundial, cresceu deveras a partir de 2008, tendo sido comercializados mais de 45 milhões de hectares, $75 \%$ na África e no Brasil e na Argentina teriam sido 3,6 milhões. $\mathrm{O}$ aumento da demanda por terras e da transferência daquelas agriculturáveis tem ocorrido nas seguintes commodities: milho, soja, cana-de-açúcar, dendê, arroz, canola, girassol e floresta plantada. ${ }^{31}$

Dessa forma, por mais que se avance no estabelecimento de vontade de tornar o acesso à alimentação igualitário em todo o mundo, há fatores de ordem financeira e econômica que tendem a impedir a sua concretização. O regime alimentar internacional ${ }^{32}$ está assentado na produção agrícola em larga escala, na homogeneização dos hábitos alimentares, nos oligopólios nos diferentes elos da cadeia produtiva dos alimentos — tradin$g s$, produção, distribuição e comercialização. Em função do desempenho do comércio das commodities, as relações capitalistas provocam contextos históricos, geopolíticos, culturais, ecológico e nutricional diferentes para o acesso à alimentação. No entanto, na consolidação do modelo do agronegócio, o contexto de acesso à alimentação que prevalece não é aquele preconizado pelas diretrizes do direito humano à alimentação. ${ }^{33}$

30 UNCTAD. Price formation in financialized commodity markets: the role of information. New York/Genebra: 2011.

31 BANCO MUNDIAL. Rising global interest in farmland: can it yield sustainable and equitable benefits? Washington D.C. 07 de setembro de 2010.

32 A compreensão da organização do capital das relações agrícolas no tempo e no espaço geográfico ao configurar, também, o processo de reprodução e produção da força de trabalho. É um conceito histórico que tem servido para demarcar, em períodos diferentes, a produção e circulação de alimentos em escala mundial conquanto se articulam e se movimentam as potências hegemônicas em cada período de tempo determinado MCMICHAEL, Philip. A food regime analysis of the 'world food crisis'. Agriculture and Human Values, Springer, 31 July, 2009.

33 MCMICHAEL, Philip. A food regime analysis of the 'world food crisis'. Agriculture and Human Values, Springer, 31 July, 2009. 


\section{Direito humano À alimentação, SEGURANÇA ALIMENTAR E NUTRICIONAL E REALIZAÇÃO PROGRESSIVA: AS EXPERIÊNCIAS NA UNIÃO EUROPEIA E AMÉRICA LATINA}

As obrigações que o direito humano à alimentação confere ao Estado consistem em: (a) proteger, ou seja, evitar que pessoas ou organizações infrinjam o direito a se alimentar de outras pessoas o que se recomenda seja evitado por meio da promulgação de leis e estabelecimento de órgãos que investiguem tais casos; (b) respeitar, isto é, os governos não devem privar ou dificultar o acesso pelos seus cidadãos ao alimento; e, por fim, (c) satisfazer - o governo deve facilitar o acesso pelos grupos vulneráveis de alimentos, bem como criar instrumentos para que esses grupos possam seguir se alimentando por si mesmos e prover alimentos nas situações em que a segurança alimentar da população estiver ameaçada por motivos alheios a sua vontade.

Dessa forma, pelo menos no âmbito das instituições governamentais e na vontade dos Estados, Europa e América se valem de normativas específicas para tratar de direito humano à alimentação e ambas se pautam na jurisdição estatal na definição do escopo e da aplicação dessa obrigação. ${ }^{34}$ Seria temerária uma comparação estrita entre União Europeia e América Latina, uma vez que se trata de economias com distintos níveis de desenvolvimento, bem como de formação econômica e histórica. Dessa forma, nesse trabalho, serão ressaltadas as medidas adotadas pelo Bloco europeu e por Estados latino-americanos para a realização do direito humano à alimentação e à segurança alimentar e nutricional (SAN).

Nessa perspectiva, e de forma comparativa, vale refletir sobre os caminhos percorridos pelo direito humano à alimentação na União Europeia, já que não foram desenhados por organismos internacionais, mas resultaram de medidas autônomas a partir da agricultura. Reconhece-se que o comércio agrícola vem sofrendo modificações, indicando que o crescimento das exportações agrícolas tem ocorrido nos países desenvolvidos, especialmente da União Europeia, “[...] cuya participación en las exportaciones agrícolas totales ha pasado de algo más del 20 por ciento a comienzos del decenio de

34 NARULA, Smita. The right to food: holding global actors accountable under international law. Columbia Journal of Transnational Law, v.44, 2006, p.690-800.
1960 a más del 40 por ciento en la actualidad." ${ }^{35}$

Verifica-se, portanto, que a agricultura foi posta como elemento-chave na consecução da integração europeia. Utilizou-se a Política Agrícola Comum (PAC), também, para lidar com diferenças de estrutura produtiva, rendimentos e custos de produção. ${ }^{36}$ Todavia, alguns problemas foram sobressaindo-se, como a redução de trabalhadores empregados nesse setor ao mesmo tempo em que se incrementavam os subsídios, do qual é possível inferir que os maiores beneficiados dessa política protecionista são os grandes produtores rurais.

Por outro lado, a Política Agrícola Comum (PAC) proporcionou vantagens à consolidação da União Europeia, enquanto bloco econômico, quais sejam: unicidade de mercados para os produtos agrícolas, preferência comunitária no comércio internacional; solidariedade financeira, em que o orçamento da União cobre todos os custos, subsídios a exportações. O fortalecimento da PAC pressupunha certo nível mínimo de produção nacional, por razões sociais ou ambientais, ou de autoabastecimento para evitar independência total do exterior. ${ }^{37}$

A partir de negociações na OMC, essa política comum teria de experimentar ${ }^{38} \mathrm{o}$ arrefecimento em seu nível de protecionismo, ao mesmo tempo em que essa possibilidade desperta a contrariedade de fazendeiros beneficiados pelos maciços subsídios governamentais. "Por isso, a PAC tem sido alvo de severas críticas desde a Rodada do Uruguai, até a presente Rodada de Doha da Organização Mundial do Comércio [...].”39 Ademais,

35 FOOD AND AGRICULTURE ORGANIZATION. El estado mundial de la agricultura y la alimentación: comercio agrícola y pobreza ¿puede el comercio obrar en favor de los pobres? Roma, 2005. Disponível em: <ftp://ftp.fao.org/docrep/fao/008/ a0050s/a0050s_full.pdf $>$. Acesso em: 12 out. 2016.

36 PERALES, R. B. Condicionamientos Internos y Externos de la PAC: elección, mantenimiento y abandono de la protección via precios. Madri: Ministério de Agricultura Pesca y Alimentacion, 1994.

37 PERALES, R. B. Condicionamientos Internos y Externos de la PAC: elección, mantenimiento y abandono de la protección via precios. Madri: Ministério de Agricultura Pesca y Alimentacion, 1994.

38 Em novembro de 2010, Bruxelas comunicou em linhas gerais a reforma da PAC. Conforme documento da Comissão Europeia, a nova orientação da política agrícola da UE será o fornecimento de alimentos seguros e em quantidade suficiente, bem como gestão sustentável dos recursos naturais. Pode-se conferir em: <http:// www.jornaldenegocios.pt $/$ home.php?template $=$ SHOWNEWS_ V2\&id $=454579>$.

39 SQUEFF, Tatiana de A. F. R. Cardoso. O Desenvolvimento da Política Agrícola Comum da União Europeia. Revista de Direito Internacional, Brasília, v. 13, n. 3, p. 374-389, 2016, p. 385. 
esse protecionismo desfavorece a cooperação internacional, especialmente no que diz respeito ao desenvolvimento do comércio internacional. Está “[...] muito mais inclinado à manutenção do status quo no que diz respeito a mercado internacional (já que dominado largamente pela União Europeia), do que efetivamente a formação de um espaço voltado à troca aberta de mercadorias, pautadas na especialidade produtiva." 40

De outro lado, tal fato, dentre outros aspectos, dá margem para mudanças no âmbito do processo de integração econômica, possibilitando aprofundar o tratamento do setor agroalimentar, em termos de incorporar assuntos relacionados com segurança do alimento. Além disso, dá espaço para o aprofundamento do comércio agrícola 'norte-sul', viabilizando, desse modo, que essa importante atividade produtiva contribua para o desenvolvimento dos países não desenvolvidos.

Portanto, a agricultura apresenta-se como setor estratégico para países desenvolvidos e em via de desenvolvimento. No grupo dos países desenvolvidos, como na União Europeia, percebe-se um intenso corporativismo para com os produtores rurais beneficiados com os incentivos à sua produção, ao mesmo tempo em que onera consumidores e a inserção internacional de Estados em desenvolvimento. ${ }^{41}$

O grupo dos países em desenvolvimento, como na América Latina, a agricultura, além de exercer funções básicas para o crescimento e desenvolvimento econômico das economias dos países, representa importante fonte de ganhos no comércio internacional.

Para perseguir los objetivos de sus políticas
alimentarias y agrícolas, los gobiernos han recurrido
a diversos instrumentos normativos, desde los
impuestos al comercio y los contingentes de
producción hasta el monopolio de las importaciones
y la prohibición de las exportaciones. Aunque sus
objetivos e instrumentos han variado con el tiempo,
en función, entre otras cosas, del nivel de desarrollo
económico y de la importancia de la agricultura en
sus economías y sociedades, los gobiernos de todo
el mundo siguen considerando que la alimentación
y la agricultura son esferas fundamentales para las
cuales es necesario establecer políticas. ${ }^{42}$

40 SQUEFF, Tatiana de A. F. R. Cardoso. O Desenvolvimento da Política Agrícola Comum da União Europeia. Revista de Direito Internacional, Brasília, v. 13, n. 3, p. 374-389, 2016, p. 385.

41 PERALES, R. B. Condicionamientos Internos y Externos de la PAC: elección, mantenimiento y abandono de la protección via precios. Madri: Ministério de Agricultura Pesca y Alimentacion, 1994. 42 FOOD AND AGRICULTURE ORGANIZATION. El estado mundial de la agricultura y la alimentación: comercio ag-
Nesse contexto, verifica-se que a segurança alimentar e nutricional possui elementos constitutivos (acesso, regularidade e qualidade) interrelacionados com o setor agrícola em termos de produção (comercialização, comércio internacional, condições do produtor). Esses elementos em conjunto induzem a afirmar que a população deve se valer de condições para se apropriar dos alimentos inócuos de maneira permanente, em quantidades adequadas para satisfazer suas necessidades nutricionais diárias. Isso só é possível diante da articulação do Estado.

Na América Latina, evidencia-se o reconhecimento de que o Estado deve assumir um compromisso efetivo em realizar o direito humano à alimentação e criar mecanismos para garantir a segurança alimentar e nutricional. Há um aparato legal que vem sendo construído desde 2003 pelos Estados latino-americanos, além dos esforços da FAO para o estabelecimento das Diretrizes Voluntárias para a promoção do Direito Humano à Alimentação em 2004, inserindo o combate à fome como um tema prioritário na agenda internacional. Afirmam-se como instrumentos para garantir o DHA: cooperações internacionais para o desenho de medidas que melhorem métodos de produção, conservação e distribuição de alimentos.

Importante ressaltar as medidas projetadas/implementadas pelos governos da América Latina, que vêm se destacando na discussão e incorporação desse eixo ético-normativo a medidas que visem desmantelar situações de insegurança alimentar e nutricional (ISAN), conforme pode-se verificar no quadro que segue:

\begin{tabular}{|l|l|l|}
\hline Países & Instrumentos & Objetivo \\
\hline Argentina & $\begin{array}{l}\text { Lei de Criação do } \\
\text { Programa Nacional } \\
\text { de Nutrição e } \\
\text { Alimentação (2003) }\end{array}$ & $\begin{array}{l}\text { Coloca o Estado no papel } \\
\text { indiscutível de garantir o } \\
\text { DHA e cidadania. Foco } \\
\text { inicial em crianças até } \\
14 \text { anos, grávidas, idosos } \\
\text { com mais de 70 anos }\end{array}$ \\
\hline Bolívia & Desnutrição Zero & $\begin{array}{l}\text { Erradicar a desnutrição } \\
\text { até 2010. Enfatiza } \\
\text { menores de 10 anos } \\
\text { e sua aplicação inicia } \\
\text { pelos municípios com } \\
\text { maior nível de ISAN }\end{array}$ \\
\hline
\end{tabular}

rícola y pobreza ¿puede el comercio obrar en favor de los pobres? Roma, 2005. Disponível em: <ftp://ftp.fao.org/docrep/fao/008/ a0050s/a0050s_full.pdf>. Acesso em: 12 out. 2016, p. 29. 


\begin{tabular}{|c|c|c|}
\hline Brasil & $\begin{array}{l}\text { Lei Orgânica de } \\
\text { Segurança Alimentar } \\
\text { e Nutricional (2006) }\end{array}$ & \begin{tabular}{|l} 
Determina a \\
criação de um \\
Sistema Nacional de \\
Segurança Alimentar e \\
Nutricional.
\end{tabular} \\
\hline Cuba & $\begin{array}{l}\text { Ratificou a } \\
\text { Declaração } \\
\text { Universal dos } \\
\text { Direitos Humanos } \\
\text { e aprovou } \\
\text { as Diretrizes } \\
\text { Voluntárias }\end{array}$ & $\begin{array}{l}\text { Em 2007, o relator } \\
\text { especial da FAO } \\
\text { destacou o empenho } \\
\text { cubano em fazer } \\
\text { cumprir o DHA. } \\
\text { O país mostraria } \\
\text { criatividade, além } \\
\text { de apoiar medidas } \\
\text { que levem a uma } \\
\text { aceitação conceitual e à à } \\
\text { realização institucional } \\
\text { desse direito. }\end{array}$ \\
\hline Equador & $\begin{array}{l}\text { Lei de Segurança } \\
\text { Alimentar e } \\
\text { Nutricional (2005) }\end{array}$ & \\
\hline Guatemala & $\begin{array}{l}\text { Lei do Sistema } \\
\text { Nacional de } \\
\text { Segurança Alimentar } \\
\text { e Nutricional (2005) }\end{array}$ & \begin{tabular}{|l} 
Seu texto é denso \\
pela forma que trata \\
a ISAN. Ressalta o \\
papel do Estado, \\
amparando-se na \\
Constituição do país. \\
Visa mobilizar amplos \\
setores da sociedade, \\
estabelece critérios \\
para transgenia e \\
comercialização. \\
Determina \\
responsabilidades \\
orçamentárias.
\end{tabular} \\
\hline México & $\begin{array}{l}\text { Lei de planejamento } \\
\text { para a soberania e } \\
\text { SAN }\end{array}$ & $\begin{array}{l}\text { Destaca ciência } \\
\text { e tecnologia na } \\
\text { preservação da } \\
\text { biodiversidade e } \\
\text { respeito à cultura } \\
\text { indígena. Propõe } \\
\text { um programa de } \\
\text { emergência para } \\
\text { erradicar a desnutrição } \\
\text { até 2015. Volta-se } \\
\text { para a produção } \\
\text { dos campesinos. } \\
\text { Preocupação com a } \\
\text { dependência alimentar } \\
\text { do país. }\end{array}$ \\
\hline Peru & $\begin{array}{l}\text { Lei do direito a } \\
\text { uma alimentação } \\
\text { adequada (2007) }\end{array}$ & $\begin{array}{l}\text { Reconhece que o } \\
\text { desenvolvimento } \\
\text { econômico requer } \\
\text { compromisso com o } \\
\text { DHA. }\end{array}$ \\
\hline
\end{tabular}

Quadro 2 - A América Latina e a realização progressiva do Direito Humano à Alimentação

Fonte: Elaboração própria.
Embora constitua uma iniciativa importante para tratar de um problema histórico-estrutural, essas leis (Quadro 2) por si só não bastam para resolver problemas de ISAN. De modo geral, essas leis falham por não terem estimado alocação orçamentária de acordo com a magnitude do problema, nem mesmo asseguram progressividade no gasto e a não regressividade nos investimentos em políticas alimentares. A documentação de casos de demandas estratégicas e de desenvolvimento de jurisprudência são, ainda, exíguos, dado o reduzido número de denúncias da violação do direito humano à alimentação.

Criar um aparato legislativo nacional e de prática administrativa imbuído da cultura dos direitos humanos representa viabilizar punições para as violações, bem como para os responsáveis por executá-las e orçamentos para induzir a realização progressiva dos direitos humanos, considerando-se que a sua realização é interdependente ao processo de desenvolvimento econômico desses países. Assim, um determinado aparato judicial/ legislativo construído deve ser respaldado por medidas como promoção do emprego, distribuição de renda, da terra dentre outras que sejam capazes de promover melhores condições de vida à população e inserção desse investimento no sistema econômico. ${ }^{43}$

O tratamento da Segurança Alimentar e Nutricional (SAN) na UE está direcionado ao compromisso em fornecer alimentos seguros, observando-se a sustentabilidade. Há um ideário de que sob o respaldo da reforma da PAC, a questão agrícola deverá ser colocada a serviço dos europeus, apesar de, em menor medida, também enfrentar problemas relacionados com distribuição, comercialização, transgenia etc., como os países latino-americanos.

Ainda, vale destacar o papel da União Europeia na assistência a nações da América Latina, Ásia e África para que elas alcancem a condição de SAN e, portanto, caminhem para a paulatina realização do DHA. Em 2009, o Bloco despendeu dois milhões de euros para apoiar pequenos agricultores de maneira a incrementar a produção agrícola em 50 países. Sua contribuição ocorre por meio da ajuda na compra de adubos e sementes, bem como fomentar programas de microcrédito para agricultores locais e melhorar condições de transporte

43 EIDE, Asbjorn. Human rights requirements to social and economic development. Food Policy, v. 21, n. 1, 1996, p. 23-39. 
na zona rural. ${ }^{44}$ Sua contribuição para esse tema segue uma perspectiva ampla e interrelacionada, associada à promoção do desenvolvimento econômico.

\section{Considerações finais}

A alimentação é fundamental à sobrevivência do ser humano. Porém, sob a lógica das relações mercantis, o acesso a ela é conduzido pelos ditames do sistema de preços de mercado, o que exclui parte da população: aquela que não conta com renda (ou renda suficiente) para adquirir gêneros alimentícios. Portanto, inacessibilidade aos alimentos e exclusão social são elementos que se inter-relacionam e se reforçam em suas mazelas. Verifica-se que, para romper com esse ciclo, é necessária a atuação do Estado, que não poderão ser resumidas a ações emergenciais (normalmente paliativas), mas por meio de medidas no âmbito da mudança estrutural. A comparação entre as ações em países desenvolvidos (União Europeia) e em desenvolvimento (América Latina) mostrou que a realização do direito humano à alimentação depende muito mais de políticas nacionais do que apenas de resoluções e tratativas de agências intergovernamentais como a ONU.

Nesse sentido, a sedimentação do conceito de direito humano à alimentação em foros de organismos internacionais e, mais normativamente, por meio de tratados, representa a busca pela construção de instrumentos, a partir da atuação do Estado, para proteger populações, sobretudo os grupos vulneráveis. Assim, respeitar, proteger e satisfazer necessidades nutricionais diárias são funções de Estado e não de benevolência.

Caso os Estados não disponham de meios para a realização do direito humano à alimentação, deverão acionar a ajuda internacional. Os mecanismos de cooperação internacional são fundamentais no fomento às políticas internas dos Estados menos desenvolvidos, destacando-se as ações da FAO. Salienta-se, também, o importante papel atribuído à sociedade (na qual está incluído o setor privado) que para além do (e com o) Estado, é responsável pela garantia do direito humano à alimentação.

44 UNIÃO EUROPEIA. Comissão Europeia. A Europa consigo: breve perspectiva do que fez a União Européia a longo deste ano. 2010. Disponível em: <file:///C:/Users/Sinara/Downloads/ NA3110661PTC_002\%20(2).pdf>. Acesso em: 15 out. 2016.
Como pode-se verificar nas análises do presente ensaio, um sistema normativo, por si só, não garante a proteção dos direitos. O Estado tem a obrigação de garantir a observância e a efetivação dos direitos humanos. No que se refere ao direito humano à alimentação, assegurá-lo, respeitá-lo implica na adoção de medidas mais incisivas do ponto de vista econômico-estrutural. A garantia de que o direito humano à alimentação será, progressivamente, realizado nos países não desenvolvidos envolve toda a comunidade internacional.

Os passos curtos e descompassados dados na direção da realização do DHA na América Latina encontram razão nas dinâmicas econômicas, nos instrumentos jurídicos e nas estratégias e escolhas estatais que vão desde o plantio até a distribuição dos alimentos. Está evidenciado, sobretudo, que o hiato existente entre as economias avançadas e as periféricas, quanto à inserção econômica internacional, reflete-se em problemas sociais relativamente graves nesses países e que, para de fato se resolverem, precisariam de medidas de cunho mais estrutural, capazes de induzir a aumentos de renda, emprego, investimento.

Fatores estruturais — distribuição de renda, reforma agrária, emprego, educação, saneamento básico — que condicionam o acesso econômico aos alimentos em países não desenvolvidos devem ser considerados em políticas públicas desses países para que, em longo prazo, a segurança alimentar e nutricional thes seja realidade. Nesse sentido, o subdesenvolvimento reforça quadros de insegurança alimentar e até mesmo os explica, justifica-se, então, que a segurança alimentar e nutricional venha representando um eixo de desenvolvimento expresso no desenho de políticas públicas nesses países. ${ }^{45}$

Fala-se neste artigo em soberania alimentar, pois buscaria permitir aos países formularem seus modelos de produção, distribuição e comercialização, sem influência da OMC e de empresas transnacionais. Entretanto, fundamental compreender a alimentação como um direito básico e não restringi-la a uma commodity.

Pode-se concluir também que, apesar de nos países não desenvolvidos o acesso a alimentos adequados não ser livre em função de fatores socioeconômicos mais complexos, é possível notar que, na União Europeia, a alimentação está sujeita, também, a problemas relacio-

45 MALUF, Renato Sérgio. Segurança Alimentar e Desenvolvimento Econômico na América Latina: o caso do Brasil. Revista de Economia Política, São Paulo, n.15, p.134-140, 1995. 
nados à distribuição, à comercialização, à inocuidade, à transgenia, à interferência do grande capital. Nesse contexto, verifica-se o maior desafio à realização progressiva do direito humano à alimentação: a evolução do sistema agroalimentar internacional. As dinâmicas que dele partem são capazes de impor padrões, cuja observância pelos países pode desencadear relativos descumprimentos ao direito a uma alimentação adequada e à segurança alimentar.

\section{REFERÊNCIAS}

ALVES, José Augusto Lindgren. Relações Internacionais e Temas Sociais. A Década das Conferências. Brasília: IBRI, 2001.

BANCO MUNDIAL. Rising global interest in farmland: Can it yield sustainable and equitable benefits? Washington D.C. 07 de setembro de 2010.

BIELEFELDT, Heiner. Filosofia dos Direitos $\mathbf{H u}-$ manos. Trad. Dankwart Bernsmüller. São Leopoldo: UNISINOS, 2000.

BOURRINET, Jacques; FLORY, Maurice. L'ordre alimentaire mondial. Economica, Paris, 1982.

CASTRO, Josué de. Geopolítica da Fome: ensaio sobre os problemas de alimentação e de população. São Paulo: Brasiliense, 1968, v.1.

EIDE, Asbjorn. Human rights requirements to social and economic development. Food Policy, v. 21, n. 1, 1996, p. 23-39.

FOOD AND AGRICULTURE ORGANIZATION. E1 estado mundial de la agricultura y la alimentación. Roma, 2009. Disponível em: <http://www.fao. org/docrep/012/i0680s/i0680s.pdf >. Acesso em: 12 out. 2016.

El estado mundial de la agricultura y

la alimentación: comercio agrícola y pobreza ¿puede el comercio obrar en favor de los pobres? Roma, 2005. Disponível em: <ftp://ftp.fao.org/docrep/fao/008/ a0050s/a0050s_full.pdf>. Acesso em: 12 out. 2016.

Diretrizes voluntárias: em apoio à realização progressiva do direito à alimentação adequada no contexto da segurança alimentar nacional. Roma, 2004. Disponível em: <http://www.fao.org/docrep/006/ Y5160s/Y5160s00.htm>. Acesso em: 12 out. 2016.
FRIEDMANN, Harriet. Uma Economia Mundial de Alimentos Sustentável. In: BELIK, W.; MALUF, R.S. (orgs.) Abastecimento e Segurança Alimentar: os limites da liberalização. Campinas: IE/Unicamp, 2000, p. 1-22.

GOMES JÚNIOR, Newton Narciso. Segurança Alimentar e Nutricional como princípio orientador de políticas públicas no marco das necessidades humanas básicas. Universidade de Brasília (UnB): Tese de Doutoramento. 2007.

GORDILlO, G.; JIMÉNEZ, F. El Nuevo Eje de la Seguridad Alimentaria. IAI-IHDP 2004 Global Environmental Change Institute on Globalization and Food Systems. São José, Costa Rica. 2004.

MALUF, Renato Sérgio (Orgs.) Abastecimento e segurança alimentar: os limites da liberalização. Campinas, SP, IE/UNICAMP, 2000.

MALUF, Renato Sérgio. Segurança Alimentar e Desenvolvimento Econômico na América Latina: o caso do Brasil. Revista de Economia Política, São Paulo, n.15, p.134-140, 1995.

MAXWELL, Simon. Food security: a post-modern perspective. Food Policy, v.21, n.2, 1996, p.155-170.

MAXWELL, Simon; SLATER, Rachel. Food policy: old and new. Food Policy, v.21, n.5-6, 2003, p. 531-553.

MCINERNEY-LANKFORD, Siobhán. Human Rights and development: a comment on challenges and opportunities from a legal perspective. Journal of Human Rights Practice, v.1, n.1, mar., 2009, p. 51-82.

MCMICHAEL, Philip. A food regime analysis of the 'world food crisis'. Agriculture and Human Values, Springer, 31 July, 2009.

NARULA, Smita. The right to food: holding global actors accountable under international law. Columbia Journal of Transnational Law, v.44, 2006, p.690-800.

ORGANIZAÇÃO DAS NAÇÕES UNIDAS. Carta das Nações Unidas. 1945. Disponível em: <http:// www.un.org/spanish/Depts/dpi/portugues/charter/ index.htm >. Acesso em: 10 out. 2016.

Declaração e Programa de Ação de Viena. 1993. Disponível em: <http://www.pge.sp.gov. br/centrodeestudos/bibliotecavirtual/instrumentos/ viena.htm >. Acesso em: 10 out. 2016.

PANITCH, Leo; GINDIN, Sam. The making of glo- 
bal capitalism: the political economy of American empire. Verso: London, New York. 2012.

PERALES, R. B. Condicionamientos Internos y Externos de la PAC: elección, mantenimiento y abandono de la protección via precios. Madri: Ministério de Agricultura Pesca y Alimentacion, 1994.

SHAIKH, Anwar. Globalization and the myth of free trade. New School University: New York, 2003.

SQUEFF, Tatiana de A. F. R. Cardoso. O desenvolvimento da política agrícola comum da União Europeia.

Revista de Direito Internacional, Brasília, v. 13, n. 3, p. 374-389, 2016.

TAKAGI, M. et al. A política de segurança alimentar e nutricional do Brasil a partir do programa Fome Zero. In: ORTEGA, A.C.; ALMEIDA FILHO, N. Desenvolvimento territorial, segurança alimentar e economia solidária. Campinas-SP: Editora Alínea. 2006, p.159-184.
TERÁN, Juan Fernando. La economía de los biocombustibles: una mirada a los proyectos hegemônicos para América Latina. In: Fernandes, Bernardo M. (Org.), Campesinato e agronegócio na América Latina: a questão agrária atual. São Paulo: Expressão Popular, 2008, 339-364.

UNCTAD. Price formation in financialized commodity markets: the role of information. New York/ Genebra: 2011.

UNCTAD. Global value chains: investment and trade for development. World Investment Report 2013. New York e Genebra, 2013.

UNIÃO EUROPEIA. Comissão Europeia. A Europa consigo: breve perspectiva do que fez a União Européia a longo deste ano. 2010. Disponível em: <file:///C:/ Users/Sinara/Downloads/NA3110661PTC_002\%20 (2).pdf>. Acesso em: 15 out. 2016. 
Para publicar na Revista de Direito Internacional, acesse o endereço eletrônico www.rdi.uniceub.br ou www.brazilianjournal.org.

Observe as normas de publicação, para facilitar e agilizar o trabalho de edição. 